\title{
Optimization and Validation of a New Method for the Production of Lipid Nanoparticles for Ophthalmic Application
}

\author{
Rosario Pignatello*, Antonio Leonardi and Sarha Cupri \\ NANO-i, Research Centre on Ocular Nanotechnology, Department of Drug Sciences, University of Catania, Italy \\ *Corresponding author: Rosario Pignatello, Department of Drug Sciences, University of Catania, viale A. Doria, 5, \\ I- 95125 Catania, Italy, E-mail: r.pignatello@unict.it
}

\begin{abstract}
Within a wider research project aimed at the pre-industrial development of nanotechnology platforms for the treatment of eye diseases, this work exploited the possibility of obtaining solid lipid nanocarriers (SLN) using ingredients and operating conditions that could be compatible with the technological requirements of medical formulations used for ophthalmic therapies and, above all, capable of an easy industrial scale-up.

In particular, we tested the possibility of adapting a production method known as Quasi-emulsion Solvent Diffusion (QESD), which already shows a number of operational advantages, such as use of low temperatures and reduced concentrations of surfactants, also to very small production volumes, compatible with expensive and/or poorly available drugs. Cationic SLN (CSLN) were produced using a commercial lipid matrix (Softisan® $\$ 100$ ), loaded with a lipophilic probe compound. These cationic carriers could be advantageous in ensuring a prolonged retention onto the negatively charged mucous surface of the cornea.

Depending on their composition, cSLN systems with a mean size around $170-250 \mathrm{~nm}$, a good size distribution profile, and a net positive charge $(+30 /+50 \mathrm{mV})$ were produced by the QESD technique. Only highly biocompatible, ICH-class 3 solvents, such as ethanol and acetone, were used. Most nanocarriers showed a good physical stability upon storage and could be produced respecting some formulation requirements, such as $\mathrm{pH}$ close to neutrality and an osmolarity compatible with the eye surface.
\end{abstract}

\section{Keywords}

SLN, Cationic nanocarriers, Ocular drug delivery, QESD method, Preformulation

\section{Introduction}

\section{The rationale for ophthalmic drug delivery}

Controlled delivery of bioactive agents to the eye surface or inner structures is a relevant area of drug research and development, though still highly challenging for the pharmaceutical technologists.

The eye is in fact protected by anatomical, biochemical and functional fences against the entry of exogenous compounds, comprising most drugs [1]. Moreover, the very limited time of contact of a topically applied formulation with the corneal surface produces an inadequate bioavailability at the level of the target sites, with the necessity of repeated instillations of the formulation $[2,3]$.

The pharmaceutical market is thus monitoring the potentiality of novel therapeutic strategies for pathological situations such as diabetic retinopathy, macular degeneration, uveitis, vascular diseases of the retina, responsible for millions cases of visual impairment or blindness in the world $[4,5]$.

However, conventional dosage forms, like eye-drops or semisolid gels and ointments, are not sufficiently valid for delivering innovative active agents, such as peptide drugs, monoclonal antibodies or gene material. This prompted to exploit the applicability to the ocular field of innovative drug delivery systems (DDS), in most cases originally developed for other routes of application, such as parenteral or oral ones.

Explorative and industrial research has been therefore focused toward novel approaches that would merge the easy of application and patient compliance, proper of classical eye-drop formulations, with an increased efficacy in terms of drug retention and/or sustained release that characterize most nanotechnology products [6].

Many nanomedicine strategies have been exploited for the diagnosis and cure of eye diseases. Ocular drug delivery systems (ODDS) range from medical application of nanomaterials, including controlled drug and gene delivery systems, to nanodevices for imaging and diagnosis, to electronic biosensors, to implantable biomaterials for tissue regeneration and prolonged local therapy [7-11].

Colloidal (nano-sized) ODDS have provided important results in recent years [12]. ODDS can be suitably engineered to protect the encapsulated drug from degradation and rapid elimination; once applied on the ocular surface, they can ensure a prolonged residence time, especially if made by muco adhesive biomaterials [13], allowing a sustained release of the drug and reducing the administered dose (costs) and frequency of instillation. If injected intraocularly, they can protect the drug from enzymatic degradation and deliver the active in a controlled manner, strongly reducing the number of potentially dangerous injections.

Citation: Pignatello R, Leonardi A, Cupri S (2014) Optimization and Validation of a New Method for the Production of Lipid Nanoparticles for Ophthalmic Application. Int J Med Nano Res 1:006

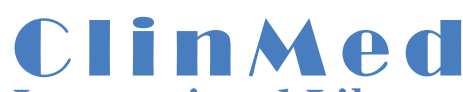

International Library

Received: October 15, 2014: Accepted: December 20, 2014: Published: December 29, 2014

Copyright: (c) 2014 Pignatello R. This is an open-access article distributed under the terms of the Creative Commons Attribution License, which permits unrestricted use, distribution, and reproduction in any medium, provided the original author and source are credited. 


\section{Lipid nanoparticles (LN) for ocular application}

Because of the potential toxicological consequences of the application of nanosized medicines to the eye tissues [14] and since, from a regulatory point of view, the applied compounds must appear as GRAS materials for pharmaceutical use, many polymers or chemically-engineered biomaterials are not accepted for ophthalmic purposes. Under this aspect, a clear advantage comes from nanocarriers produced using natural lipids, or other biocompatible and physiologically accepted lipid materials and surfactants.

From a technological point of view, LN combine the advantages of polymeric nanoparticles, in terms of stability, modulated drug delivery and good production scalability, with the high biocompatibility of liposomes and nanocarriers made by natural materials. $\mathrm{LN}$ have been proposed for various administration routes, including the application to the ocular surface and eye posterior segment [15-17]; actually, LN can also be sterilized by different methods, thus complying with the various routes of ocular application [18]. Apart the above favorable characteristics, LN have shown a number of intrinsic advantages relevant for an ocular application: i) the possibility of a controlled/ extended drug release ii) bioadhesive properties, that prolong the residence time at ocular surface iii) their small size would facilitate the penetration and passage across the cornea to the anterior chamber or inner eye structures, facilitating the transport of the drug to the different compartments of the eye iv) they can be formulated as 'classical' eye-drops, with a consequent high patient comfort and compliance; v) a very peculiar feature, discussed by Gan et al. [19], is that some LN have properties similar to those of the tear film; their topical applicationcan enhance the aqueous layer of tear film and moisten the cornea.

Among lipid-based nanocarriers, solid lipid nanoparticles (SLN) possess a lipid core, solid at room temperature, stabilized by a layer made by a surfactant or a mixture of tenside agents $[20,21]$. SLN are produced by different methods, including high-energy technologies, such as high-pressure homogenization (cold- or hot-HPH), and low energy emulsification processes (solvent emulsification-evaporation or diffusion, solvent injection, microemulsion, phase inversion temperature (PIT) method), that allow to originate nanoparticles using a minimum energy [15,20-23]. The production method will ultimately affects the nanoparticle mean size and physical stability, drug loading capacity and release profile, and so on. Up to present, only few processes, such as HPH and microemulsion dilution methods have shown to be able to produce SLN on an industrial scale.

We have recently proposed a method for producing $\mathrm{LN}$ that intrinsically encompasses a number of positive aspects for an ophthalmic or a parenteral formulation. The Quasi-Emulsion Solvent Diffusion method (QESD), detailed in the Experimental section, was originally proposed for the preparation of polymeric nanosystems [24-26], but has been later exploited for the formulation of SLN [2729]. It allows to work under operative and formulation conditions compatible with the requirements for an ophthalmic dosage form. The drug and lipid material(s) are dissolved in water-mixable, volatile solvents, like ethanol and acetone that belong to the Class 3 of residual solvents (ICH Q3C) i.e., considered widely suitable for most drug products. Secondly, the aqueous phase can consist of pharmaceuticalgrade water or buffer solution, or another physiologically compatible and, if necessary, sterile medium (e.g., saline). The method requires only very low concentrations of a surfactant agent to produce the SLN that can be chosen to be highly compatible with the eye [30]. Finally, mixing and homogenization of the organic and aqueous phases is made at very low temperatures, thus preserving the integrity of any thermo-sensitive compound.

The present work belongs to a wider research project at NANO-i Research Center, focused on the pre-industrial development of nanotechnology platforms suitable for the treatment of diseases of the anterior and posterior eye segments. We thus exploited the possibility of obtaining SLN using ingredients and operating conditions that could be compatible with the technological features required for an ophthalmic drug formulation and, at the same time, appropriate for an easy, future industrial scale-up process.

In particular, we tested the possibility of optimizing the QESD method for producing an ophthalmic nanotechnological formulation, by using a very low surfactant concentration, solvents highly biocompatible with the eye tissues and, above all, working with very small production volumes, an approach that could be beneficial when expensive or scarcely available drugs must be managed.

Positively-charged (cationic) SLN were selected (cSLN), obtained by adding a cationic lipid (dimethyldioctadecylammonium bromide; $\mathrm{DDAB}$ ) to the main lipid. These cSLN systems could be advantageous for the delivery of drugs to the ocular surface, which possesses a negative charge due to the mucin layer. The electrostatic interaction of nanoparticles with mucin may ensure a longer residence time and an overall better performance of the drug carrier system [17,31]. Some Authors also showed a better transcorneal penetration of drugs loaded in CSLN [32,33].

In this preliminary study, the SLN were not loaded with an active compound, but a colored probe, Oil Red O was used as a lipophilic model compound.

\section{Experimental Part}

\section{Materials}

The lipid used for the production of the SLN [Softisan ${ }^{\circ}$ S100 (S100)] is a mixture of triglycerides of saturated C10-C18 fatty acids, supplied by Sasol GmBH (Germany); Oil Red O, Tween 80, DDAB, PBS (phosphate buffer solution, $\mathrm{pH}$ 7.4) and sodium chloride were purchased from Sigma-Aldrich Chimica srl (Milan, Italy). Ethanol and acetone (analytical grade) were purchased from Merck (VWR International PBI srl, Milan, Italy); HPLC-grade water was used during the work (Merck). Phosphate buffer solutions were prepared as described in Italian Pharmacopoeia (F.U.I., X Ed.), with the following compositions: phosphate buffer solution, $\mathrm{pH}$ 6.6: $250 \mathrm{ml}$ of $0.2 \mathrm{M}$ monobasic potassium phosphate and $89 \mathrm{ml}$ of $0.2 \mathrm{~N}$ sodium hydroxide, water q.b. to $1 \mathrm{l} ; 0.067 \mathrm{M}$ phosphate buffer solution, $\mathrm{pH}$ 7.0: $38.9 \mathrm{ml}$ of a $0.908 \%(\mathrm{w} / \mathrm{v})$ solution of monobasic potassium phosphate added to $61.1 \mathrm{ml}$ of a $2.38 \%(\mathrm{w} / \mathrm{v})$ solution of bibasic sodium phosphate; phosphate buffer solution, $\mathrm{pH}$ 7.4: $393.4 \mathrm{ml}$ of $0.1 \mathrm{~N}$ sodium hydroxide mixed with $250 \mathrm{ml}$ of $0.2 \mathrm{M}$ monobasic potassium phosphate.

\section{Preparation of the SLN with the QESD method}

The SLN were prepared by an adapted QESD method. In a preliminary protocol, the procedure encompassed the dissolution of $\mathrm{S} 100, \mathrm{DDAB}$, and Oil Red $\mathrm{O}$ in $2 \mathrm{ml}$ of an ethanol/acetone mixture $(1: 1, \mathrm{v} / \mathrm{v})$. This solution was slowly injected, through a thin Teflon tube connected to an insulin syringe, into a 25 -ml glass tube containing 10 $\mathrm{ml}$ of the aqueous phase and kept at $0^{\circ} \mathrm{C}$ in an ice bath. The mixing of the two phases was supported through a constant stirring at $13500 \mathrm{rpm}$, by an Ultra-Turrax T25 equipped with a G10 dispersing accessory (IKA GmbH, Königswinter, Germany). For the preliminary experiments, the aqueous phase consisted of a water solution of Tween $80(0.05 \%, \mathrm{w} / \mathrm{v})$. After $15 \mathrm{~min}$ of high-speed stirring, the mixture was sonified (Branson 5002, VWR International PBI srl, Milan, Italy) for $25 \mathrm{~min}$ at room temperature, to homogenize the dispersion. Samples were then left to stir for approximately $8 \mathrm{~h}$ on a magnetic plate at room temperature, to allow the complete evaporation of the solvents.

Table 1: Formulation variables for the SLN (values are reported as $\%, w / v$ )

\begin{tabular}{|c|c|c|c|c|}
\hline Batch code & S100 & DDAB & Tween 80 & Oil Red O \\
\hline S1A & 1 & 0.02 & 0.05 & 0.05 \\
\hline S2A & 2 & 0.02 & 0.05 & 0.05 \\
\hline S3A & 3 & 0.02 & 0.05 & 0.05 \\
\hline S1B & 1 & 0.03 & 0.05 & 0.05 \\
\hline S2B & 2 & 0.03 & 0.05 & 0.05 \\
\hline S3B & 3 & 0.03 & 0.05 & 0.05 \\
\hline S2C & 2 & - & 0.05 & 0.05 \\
\hline
\end{tabular}


For the aims of this study, the cSLN were prepared using as a variable the amount of lipid and/or DDAB, whereas the amount of Oil Red O and Tween 80 were kept constant (Table 1).

\section{Production yield}

To verify the influence of the operating conditions upon the properties of the SLN and the production yield, some variables were applied (cf. Table 4):

a) Initial percentage of the lipid $(1,2$ or $3 \%, w / v)$;

b) Volume of the aqueous phase (10 or $50 \mathrm{ml})$;

c) Homogenizer accessory (probe) (IKA S25N 10G or 8G);

d) Type of tube (glass or plastic) containing the aqueous phase. In all the above batches, the volume of organic solution of the liposoluble ingredients was kept constant at $2 \mathrm{ml}$.

After the homogenization with the Ultra-Turrax T-25, the coarse material remained adherent to the walls of the container and to the probe was recovered with acetone and collected in a weighted glass flask. The solution was dried under vacuum and then frozen and freeze dried (Edwards Modulyo) for $24 \mathrm{~h}$. From the weight of the lipid, the percent production yield was calculated according to following equation:

Production yield $=[($ initial amount of lipid - amount of lipid in the flask) $\times 100$ ] /initial amount of lipid.

\section{Size analysis}

The mean size (Z-ave) and polydispersity index (PDI) of the cSLN were determined by dynamic light scattering using a Zetasizer Nano ZS90 (Malvern, UK) connected to a PC and using the PCS software (v1.27) by Malvern Instruments for data collecting and processing. The instrument operates using $90^{\circ}$ scattering optics. Each SLN batch was 10 -fold diluted with HPLC-grade waterand analyzed within $24 \mathrm{~h}$ from the preparation. The reported values (Table 2) are the mean \pm $\mathrm{SD}$ of 90 measurements (three sets of 10 measurements in triplicate).

\section{Zeta potential determination}

The electrophoretic mobility and Zeta potential(PZ) were determined by the technique of laser doppler anemometer with the same Zetasizer Nano ZS90.The instrumentation consists of a He-Ne laser with a power of $4 \mathrm{~mW}$ at a wavelength of $633 \mathrm{~nm}$. Each sample was diluted 1:100 with HPLC-grade water for the test. Up to 100 measurements on each sample were registered at room temperature to calculate the electrophoretic mobility and, using the Smoluchowski constant (Ka) with a value of 1.5 , the corresponding Zeta potential value.

\section{Determination of drug content}

The drug content indicates the total amount of Oil Red O in each nanoparticle batch (both encapsulated in the SLN and remained in the aqueous phase of the nanosuspension). One hundred microliters of each preparation were diluted tenfold with ethanol, heating at $50^{\circ} \mathrm{C}$ in a water bath under vigorous magnetic stirring. This procedure allowed the disruption of the SLN matrix and the release of the entrapped probe. The mixture was then filtered $(0.22 \mu \mathrm{mAcrodisc}$ GHP syringe filters) and analyzed by UV spectrophotometry for quantification of the probe. Standard solutions of Oil Red O in ethanol ( $\lambda$ max: 516.5 $\mathrm{nm})$ gave a linear response in the range 5 to $40 \mu \mathrm{g} / \mathrm{ml}(\mathrm{r} 2=0.9999)$.

\section{pH and osmolarity}

The cSLN were diluted at various sample-to-buffer ratios (1:1, 1:2, 1:5) using three different buffer solutions, at $\mathrm{pH} 6.6,7.0$, and 7.4. All the buffer solutions were prepared daily. Immediately before and after each dilution, the values of $\mathrm{pH}$ (Crison BASIC 20 pHmeter, Hach Lange srl, Lainate, Italy), and osmolarity (Osmomat 030-D cryoscopic osmometer, Gonotech, Berlin, Germany) were determined.

\section{Stability studies}

The mid-term physical stability of the SLN liquid dispersions was assessed by measuring the $\mathrm{Z}$-ave, $\mathrm{PDI}$ and $\mathrm{ZP}$ values after storage at room temperature $\left(20-25^{\circ} \mathrm{C}\right)$ or in a refrigerator $\left(4 \pm 1^{\circ} \mathrm{C}\right)$ in closed glass containers. Each sample was checked at 30 days intervals up to three months.

\section{Preparation of cSLN with different media}

In order to produce formulations compatible with the eye tissues, thereby isoosmotic and isohydric, SLN batches were also prepared using, instead of water as the aqueous phase, either physiological saline $(\mathrm{NaCl}, 9 \mathrm{~g} / \mathrm{l})$ or $\mathrm{PBS}, \mathrm{pH} 7.4$, both added with $0.05 \%(\mathrm{w} / \mathrm{v})$ Tween 80 . The other operating conditions were similar to those reported before.

\section{Results and Discussion}

\section{Preparation of the cSLN}

The SLN, whose composition is summarized in Table 1, were prepared according to an adaptation of the method known as QuasiEmulsion Solvent Diffusion (QESD) [25,27,29]. The main advantage of the QESD preparation technique is to avoid the use of potentially harmful organic solvents (such as dichloromethane, toluene, etc.),

Table 2: Physico-chemical properties of the SLN batches. Values refer to mean \pm S.D. of samples analyzed within $24 \mathrm{~h}$ from the production.

\begin{tabular}{|c|c|c|c|}
\hline Batch code & Z-ave $(\mathbf{n m})$ & PDI & ZP $(\mathbf{m V})$ \\
\hline S1A & $233.9 \pm 2.33$ & $0.224 \pm 0.030$ & $+47.4 \pm 2.17$ \\
\hline S2A & $245.0 \pm 2.11$ & $0.270 \pm 0.010$ & $+53.0 \pm 3.20$ \\
\hline S3A & $213.9 \pm 1.47$ & $0.210 \pm 0.022$ & $+47.4 \pm 0.97$ \\
\hline S1B & $253.1 \pm 3.84$ & $0.233 \pm 0.021$ & $+30.8 \pm 2.31$ \\
\hline S2B & $264.9 \pm 6.59$ & $0.268 \pm 0.027$ & $+36.5 \pm 2.08$ \\
\hline S3B & $322.2 \pm 4.73$ & $0.259 \pm 0.016$ & $+46.5 \pm 0.42$ \\
\hline S2C & $167.8 \pm 4.99$ & $0.444 \pm 0.080$ & $-26.0 \pm 0.11$ \\
\hline
\end{tabular}
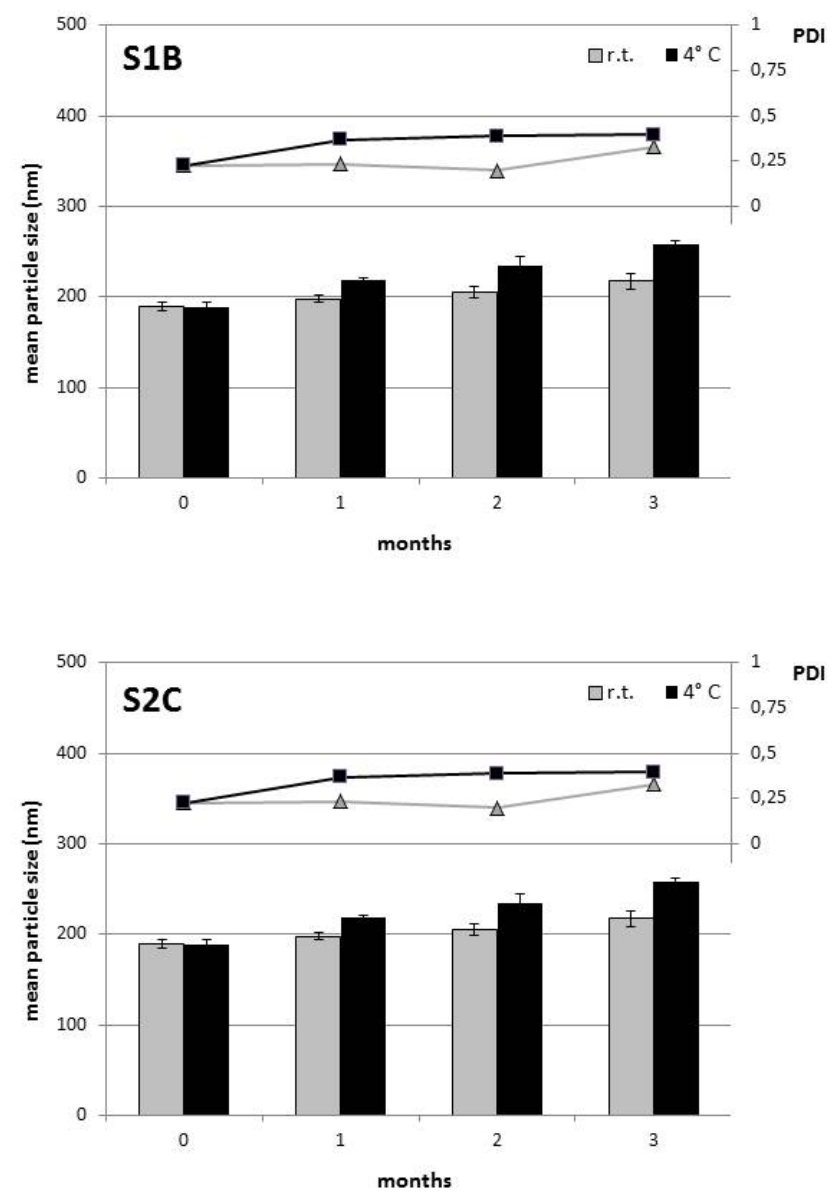

Figure 1: Changes of mean particle size and PDI values upon storage of cationic SLN (S1B) and neutral SLN (S2C) at room temperature $\left(20-25^{\circ} \mathrm{C}\right)$ or at $4 \pm 1^{\circ} \mathrm{C}$. Samples were stored in closed glass vials 
frequently required for the preparation of lipid-based micro-and nanoparticles by solvent evaporation methods. This choice is in most cases driven by the limited solubility of the lipid materials in more polar solvents and represents an enormous drawback when the delivery system must be used on the delicate tissues of the eye. Conversely, in the QESD method highly biocompatible solvents can be used, such as acetone or ethanol.

One formulation was produced without the addition of DDAB (batch S2C), obtaining negatively charged nanoparticles (cf. Table 2).

As a model lipophilic compound, Oil Red $\mathrm{O}$ was loaded in the SLN, a diazo-compound with coloring power for triglycerides and biological membranes.

\section{SLN analysis}

The mean particle sizes (Z-ave), PDI and Zeta potential (ZP) values for the prepared systems are reported in Table 2 .

The particle size of most SLN systems was comprised around 200$250 \mathrm{~nm}$, i.e. within values highly suitable for an ophthalmic application and, noteworthy, for being sterilized by $0.22 \mu \mathrm{m}$ membrane filtration. Furthermore, previous studies of ours showed that this kind of nanoparticles can be also sterilized by autoclaving (Pignatello et al., unpublished results). The PDI values in almost all the systems were very low $(<0.3)$, confirming their homogeneity in size. As foreseen, all the cSLN batches gave markedly positive ZP values.

\section{Stability studies}

All the prepared SLN were submitted to a short-term (1 month) stability test, upon storage at room temperature or at $4^{\circ} \mathrm{C}$. Table 3 gathers the measured experimental values that demonstrate a general invariance of the mean technological parameters. Two sample batches, representing cationic (S1B) and neutral SLN (S2C), where stored for a mid-term period ( 3 months) in the same conditions. As Figure 1 reports, the mean particle size and PDI showed only marginal increases during storage, indicating a good physical stability. In particular, storage at room temperature appeared to be a better condition than at refrigerator temperature. These findings would exclude any important aggregation or degradation phenomenon, and support the suitability of this preparative technique for producing homogeneous lipid nanomatrices.

\section{Formulation variables}

During the production process, part of the lipid material remained adherent to the walls of the glass tube and the homogenizer probe. By considering that in this study we also tested the possibility of 'scaling-down' the QESD method to small production volumes, such loss of material could be critical for the quality of the final systems. Therefore, we investigated how to optimize the production yield, avoiding or reducing such phenomenon.

A pair of cSLN systems were selected, namely batches S1A and S2A, which showed suitable technological features, in terms of size and PDI values (cf. Table 2), to study the effect of the following operating variables:

- The material of the tube (glass or plastic);

- Volume of the aqueous phase (from 10 to $50 \mathrm{ml}$ );

- Diameter of Ultra-Turrax accessory (probe), using the smaller IKA S25N-8G instead of the S25N-10G.

As Table 4 shows, using the smaller $8 \mathrm{G}$ accessory in particular led to a population of SLN with optimal size values (below $200 \mathrm{~nm}$ ) and homogeneity (PDI 0.15-0.2). In the meantime, this change allowed to reduce dramatically the loss of lipid material inside the preparation apparatus.

Conversely, the volume increase of the aqueous phase from 10 to $50 \mathrm{ml}$ did not exert a positive effect on the mean size of nanoparticles, and neither on the percent recovery of material (production yield), which remained almost unvaried.

Finally, using a plastic tube instead of a glass one also allowed to double the final yield and to produce nanoparticles with a smaller

Table 3: Physico-chemical parameters of SLN stored for 1 or 3 months at room temperature $\left(20-25^{\circ} \mathrm{C}\right)$ or at $4 \pm 1^{\circ} \mathrm{C}$.

\begin{tabular}{|c|c|c|c|c|c|c|}
\hline Batch code & \multicolumn{3}{|c|}{ Room temperature } & \multicolumn{2}{c|}{$4^{\circ} \mathbf{C}$} \\
\hline & Z-ave (nm) & PDI & ZP (mV) & Z-ave (nm) & $0.314 \pm 0.036$ \\
\hline S1A & $386.7 \pm 5.59$ & $0.314 \pm 0.036$ & $+26.9 \pm 1.44$ & $386.7 \pm 5.59$ & $+26.9 \pm 1.44$ \\
\hline S2A & $344.9 \pm 6.52$ & $0.259 \pm 0.004$ & $+57.4 \pm 0.15$ & $344.9 \pm 6.52$ & $0.259 \pm 0.004$ \\
\hline S3A & $300.2 \pm 4.00$ & $0.242 \pm 0.014$ & $+53.1 \pm 0.96$ & $300.2 \pm 4.00$ & $0.242 \pm 0.014$ \\
\hline S1B & $273.4 \pm 2.45$ & $0.256 \pm 0.111$ & $+34.3 \pm 3.00$ & $273.4 \pm 2.45$ & $0.256 \pm 0.111$ \\
\hline S2B & $312.5 \pm 2.44$ & $0.317 \pm 0.039$ & $+45.5 \pm 1.21$ & $312.5 \pm 2.44$ & $0.317 \pm 0.039$ \\
\hline S3B & $315.0 \pm 5.76$ & $0.273 \pm 0.008$ & $+38.7 \pm 0.96$ & $315.0 \pm 5.76$ & $0.273 \pm 0.008$ & $+34.3 \pm 3.00$ \\
\hline S2C & $374.3 \pm 3.06$ & $0.289 \pm 0.026$ & $-36.6 \pm 3.00$ & $374.3 \pm 3.06$ & $0.289 \pm 0.026$ & $+38.7 \pm 0.96$ \\
\hline
\end{tabular}

Table 4: Physico-chemical properties of the cSLN S1A and S2A produced in different operative conditions. The specific variable(s) which characterize each batch [volume of the aqueous phase (10 or $50 \mathrm{ml}$ ); glass or plastic tube; S25N-10G or S25N-8G probe accessory] are evidenced in bold under the column 'Conditions'.

\begin{tabular}{|c|c|c|c|c|c|c|}
\hline Batch & Conditions & Z-ave (nm) & PDI & $\mathrm{ZP}(\mathrm{mV})$ & Yield \% & Drug content $(\mu \mathrm{g} / \mathrm{ml})$ \\
\hline S1A & $\begin{array}{c}10 \mathrm{ml} \\
\text { glass } \\
\mathrm{S} 25 \mathrm{~N}-10 \mathrm{G}\end{array}$ & $233.9 \pm 2.33$ & $0.224 \pm 0.030$ & $+47.4 \pm 2.17$ & 66.76 & $245 \pm 32$ \\
\hline S1A & $\begin{array}{c}\mathbf{5 0} \mathbf{~ m l} \\
\text { glass } \\
\mathrm{S} 25 \mathrm{~N}-10 \mathrm{G}\end{array}$ & $253.8 \pm 2.46$ & $0.206 \pm 0.044$ & $+48.8 \pm 2.00$ & 70.80 & $570 \pm 32$ \\
\hline S1A & $\begin{array}{c}10 \mathrm{ml} \\
\text { glass } \\
\text { S25N-8G }\end{array}$ & $194.6 \pm 0.21$ & $0.148 \pm 0.020$ & $+44.3 \pm 1.00$ & 100.00 & $429 \pm 22$ \\
\hline S2A & $\begin{array}{c}10 \mathrm{ml} \\
\text { glass } \\
\mathrm{S} 25 \mathrm{~N}-10 \mathrm{G}\end{array}$ & $245.0 \pm 2.11$ & $0.270 \pm 0.010$ & $+53.0 \pm 3.20$ & 31.90 & $278 \pm 15$ \\
\hline S2A & $\begin{array}{c}10 \mathrm{ml} \\
\text { plastic } \\
\mathrm{S} 25 \mathrm{~N}-10 \mathrm{G}\end{array}$ & $207.3 \pm 4.56$ & $0.188 \pm 0.013$ & $+57.0 \pm 1.04$ & 67.30 & $108 \pm 23$ \\
\hline S2A & $\begin{array}{c}\mathbf{5 0} \mathbf{~ m l} \\
\text { glass } \\
\mathrm{S} 25 \mathrm{~N}-10 \mathrm{G}\end{array}$ & $273.4 \pm 6.16$ & $0.342 \pm 0.018$ & $+29.4 \pm 0.64$ & 35.30 & $234 \pm 31$ \\
\hline S2A & $\begin{array}{c}10 \mathrm{ml} \\
\text { plastic } \\
\text { S25N-8G }\end{array}$ & $182.3 \pm 7.01$ & $0.191 \pm 0.009$ & $+49.6 \pm 0.34$ & 89.88 & $244 \pm 22$ \\
\hline
\end{tabular}


Table 5: $\mathrm{pH}$ values of the cSLN after the preparation or upon dilution with phosphate buffer solutions. The specific variable(s) which characterize each batch [volume of the aqueous phase (10 or $50 \mathrm{ml}$ ); glass or plastic tube; $\mathrm{S} 25 \mathrm{~N}-10 \mathrm{G}$ or S25N-8G probe accessory] are evidenced in bold under the column 'Conditions'.

\begin{tabular}{|c|c|c|c|c|}
\hline Batch & $\begin{array}{c}\text { Operative } \\
\text { conditions }\end{array}$ & $\begin{array}{l}\text { Phosphate buffer } \\
\text { solution (pH) }\end{array}$ & Dilution ratio (v/v) & Final measured $\mathrm{pH}$ \\
\hline \multirow[t]{4}{*}{$\begin{array}{c}\text { S2A } \\
\text { (initial } \mathrm{pH}: 5.90 \text { ) }\end{array}$} & $\begin{array}{c}10 \mathrm{ml} \text { plastic } \\
\text { S25N-10G }\end{array}$ & 6.6 & $1: 1$ & 6.14 \\
\hline & & & $1: 5$ & 6.50 \\
\hline & & 7.4 & $1: 1$ & 7.15 \\
\hline & & & $1: 5$ & 7.28 \\
\hline \multirow[t]{2}{*}{$\begin{array}{c}\text { S2A } \\
\text { (initial } \mathrm{pH}: 6.38 \text { ) }\end{array}$} & $\begin{array}{l}10 \mathrm{ml} \text { glass } \\
\text { S25N-10G }\end{array}$ & 7.4 & $1: 1$ & 7.26 \\
\hline & & & $1: 5$ & 7.23 \\
\hline \multirow[t]{8}{*}{$\begin{array}{c}\text { S1A } \\
\text { (initial } \mathrm{pH}: 6.04 \text { ) }\end{array}$} & $\begin{array}{l}50 \mathrm{ml} \text { glass } \\
\text { S25N-10G }\end{array}$ & 6.6 & $1: 1$ & 6.83 \\
\hline & & & $1: 5$ & 6.63 \\
\hline & & 7.0 & $1: 1$ & 7.12 \\
\hline & & & $1: 2$ & 7.17 \\
\hline & & & $1: 5$ & 7.00 \\
\hline & & 7.4 & $1: 1$ & 7.38 \\
\hline & & & $1: 2$ & 7.47 \\
\hline & & & $1: 5$ & 7.31 \\
\hline \multirow[t]{6}{*}{$\begin{array}{c}\text { S2A } \\
\text { (initial } \mathrm{pH}: 6.68 \text { ) }\end{array}$} & $\begin{array}{l}50 \mathrm{ml} \text { glass } \\
\mathrm{S} 25 \mathrm{~N}-10 \mathrm{G}\end{array}$ & 7.0 & $1: 1$ & 7.18 \\
\hline & & & $1: 2$ & 7.19 \\
\hline & & & $1: 5$ & 6.97 \\
\hline & & 7.4 & $1: 1$ & 7.41 \\
\hline & & & $1: 2$ & 7.47 \\
\hline & & & $1: 5$ & 7.25 \\
\hline \multirow[t]{2}{*}{$\begin{array}{c}\text { S1A } \\
\text { (initial } \mathrm{pH}: 6.88 \text { ) }\end{array}$} & $\begin{array}{l}10 \mathrm{ml} \text { glass } \\
\text { S25N-8G }\end{array}$ & 7.0 & $1: 2$ & 7.18 \\
\hline & & 7.4 & $1: 2$ & 7.47 \\
\hline
\end{tabular}

Table 6: Osmolarity of the cSLN batch S1A produced in different aqueous phases.

\begin{tabular}{|l|c|}
\hline \multicolumn{1}{|c|}{ Aqueous phase } & Osmolarity (mOsmol $/ \mathbf{l})$ \\
\hline PBS + Tween $^{\circledR} 80(0.05 \%, \mathrm{w} / \mathrm{v})$ & 338 \\
\hline $\mathrm{NaCl}(0.9 \mathrm{~g} / \mathrm{l})+$ Tween $^{\circledR} 80(0.05 \%, \mathrm{w} / \mathrm{v})$ & 302 \\
\hline
\end{tabular}

mean size and PDI (see, for instance, the batch S2A produced in the last conditions).

A concomitant reduction of the amount of loaded drug was observed using a plastic tube; however, such parameter apparently did not give significant information to validate the role of the different operating variables. It must be considered that Oil Red O is a very lipophilic compound ( $\log \mathrm{P} 9.4)$ [34], thereby, the measured drug content values (expressed as the sum of the probe encapsulated in the SLN and that remained in the aqueous medium) was affected by its very limited solubility. In the presence of a drug molecule, these parameters would deserve to be studied with more attention and optimized as a function of any process variable.

\section{Assessment of $\mathrm{pH}$ and osmolarity}

To produce nanoparticle systems compatible with the eye tissues, the values of $\mathrm{pH}$ and osmolarity of the cSLN were analyzed. As required by the European Pharmacopoeia, all the liquid formulations that are intended for ophthalmic use must fall into defined values: namely, a pH between 6.8 and 7.4 could represent an optimal compromise between solubility/stability issues of the drug and eye tissue tolerability. The tonicity limits may actually range from about 171 to about $1711 \mathrm{mOsmol} / \mathrm{l}$ without relevant discomfort to the eye, although for most eye drop formulations a value approaching isotonicity ( $308 \mathrm{mOsmol} / \mathrm{l})$ is usually accepted.

Since the $\mathrm{pH}$ value of the original SLN systems was slightly out of the above limits, it was adjusted by addition of appropriate phosphate buffer solutions, at different dilutions (Table 5). In this way, the $\mathrm{pH}$ of the final formulations was conveyed towards the admitted limits.

Concerning the osmolarity of the cSLN preparations, the S1A batch was produced using either PBS ( $\mathrm{pH} 7.4$ ) or saline as the aqueous phase, always in the presence of the original concentration of surfactant. As Table 6 reports, in both cases a value compatible with the ocular application was achieved.

\section{Conclusions}

The main purpose of this experimental work has been the development and validation of a technique (QESD), previously used to obtain polymer- and lipid-based nanocarriers, for the production of formulations with a potential ophthalmic application. To this end, attention has been devoted to the ingredients of the produced SLN systems, and in particular solvents and type/concentration of the required surfactant, operating temperature conditions and, most importantly, the possibility of producing the nanocarriers using very small batch volumes, that can be suitable for very expensive drugs, or compounds active at very low concentrations.

On the other hand, because of our general interest in SLN as a potential drug delivery platform for ophthalmic use, other formulative parameters were evaluated and optimized, to accomplish with the technological requirements of a nanocarrier system to be clinically appropriate for the topical application to the eye.

Using a commercial, highly biocompatible lipid material (a mixture of glycerides of saturated fatty acids), and other opportunely selected components, it was possible to validate the QESD method for producing small volumes of SLN dispersions, loaded with a model lipophilic molecule, which exhibit physico-chemical and technological properties (mean particle size and size homogeneity, net positive surface charge, high drug encapsulation efficiency, stability) all relevant and encouraging from the point of view of an ocular application.

Basing on these preliminary studies, some of the proposed cSLN can be proposed as a technologically advanced nanocarrier for the ophthalmic controlled release of different therapeutic agents.

\section{References}

1. Kokate A, Marasanapalle VP, Jasti BR, Li X (2006) In: Li X, Jasti BR, Eds. Physiological and biochemical barriers to drug delivery. Design of Controlled Release Drug Delivery Systems. McGraw-Hill, 41-73.

2. Hugues FC, Le Jeunne C (1993) Systemic and local tolerability of ophthalmic drug formulations. An update. Drug Saf 8: 365-380. 
3. Davies NM (2000) Biopharmaceutical considerations in topical ocular drug delivery. Clin Exp Pharmacol Physiol 27: 558-562.

4. http://www.nei.nih.gov/strategicplanning/np_retinal.asp

5. Ratnapriya R, Chew EY (2013) Age-related macular degeneration-clinical review and genetics update. Clin Genet 84: 160-166.

6. Bucolo C, Drago F, Salomone S (2012) Ocular drug delivery: a clue from nanotechnology. Front Pharmacol 3: 188.

7. Jain KK (2008) In: Jain KK (Ed). Nano-Ophthalmology. The Handbook of Nanomedicine. Springer, 295-301.

8. Kearns VR, Williams RL (2009) Drug delivery systems for the eye. Expert Rev Med Devices 6: 277-290.

9. Eljarrat-Binstock E, Pe'er J, Domb AJ (2010) New techniques for drug delivery to the posterior eye segment. Pharm Res 27: 530-543.

10. Zarbin MA, Montemagno C, Leary JF, Ritch R (2010) Nanomedicine in ophthalmology: the new frontier. Am J Ophthalmol 150: 144-162.

11. Yasin MN, Svirskis D2, Seyfoddin A2, Rupenthal ID3 (2014) Implants for drug delivery to the posterior segment of the eye: A focus on stimuli-responsive and tunable release systems. J Control Release 196C: 208-221.

12. Pignatello R, Puglisi G (2011) Nanotechnology in ophthalmic drug delivery: a survey of recent developments and patenting activity. Rec Pat Nanomed1: 42-54

13. du Toit LC, Pillay V, Choonara YE, Govender T, Carmichael T (2011) Ocular drug delivery - a look towards nanobioadhesives. Expert Opin Drug Deliv 8 71-94.

14. Prow TW (2010) Toxicity of nanomaterials to the eye. Wiley Interdiscip Rev Nanomed Nanobiotechnol 2: 317-333.

15. Sawant KK, Dodiya SS (2008) Recent advances and patents on solid lipid nanoparticles. Recent Pat Drug Deliv Formul 2: 120-135.

16. Carbone C, Leonardi A, Cupri S, Puglisi G, Pignatello R (2014) Pharmaceutical and biomedical applications of lipid-based nanocarriers. Pharm Pat Anal 3 $199-215$

17. Fangueiro JF, Andreani T, Egea MA, Garcia ML, Souto SB, et al. (2014) Design of cationic lipid nanoparticles for ocular delivery: development characterization and cytotoxicity. Int J Pharm 461: 64-73.

18. Seyfoddin A, Shaw J, Al-Kassas R (2010) Solid lipid nanoparticles for ocular drug delivery. Drug Deliv 17: 467-489.

19. Gan L, Wang J, Jiang M, Bartlett H, Ouyang D, et al. (2013) Recent advances in topical ophthalmic drug delivery with lipid-based nanocarriers. Drug Discov Today 18: 290-297.

20. Müller RH, Shegokar R, Keck CM (2011) 20 years of lipid nanoparticles (SLN and NLC): present state of development and industrial applications. Curr Drug Discov Technol 8: 207-227.
21. Carbone C, Cupri S, Leonardi A, Puglisi G, Pignatello R (2013) Lipid-based nanocarriers for drug delivery and targeting: a patent survey of methods of production and characterization. Pharm Pat Anal 2: 665-677.

22. Carbone C, Tomasello B, Ruozi B, Renis M, Puglisi G (2012) Preparation and optimization of PIT solid lipid nanoparticles via statistical factorial design. Eur J Med Chem 49: 110-117.

23. Battaglia L, Gallarate M (2012) Lipid nanoparticles: state of the art, new preparation methods and challenges in drug delivery. Expert Opin Drug Deliv 9: 497-508

24. Kawashima Y, Niwa T, Handa T, Takeuchi H, Iwamoto T, et al. (1989) Preparation of controlled-release microspheres of ibuprofen with acrylic polymers by a novel quasi-emulsion solvent diffusion method. J Pharm Sci 78: $68-72$.

25. Pignatello R, Bucolo C, Ferrara P, Maltese A, Puleo A, et al. (2002) Eudragit RS100 nanosuspensions for the ophthalmic controlled delivery of ibuprofen. Eur J Pharm Sci 16: 53-61.

26. Pignatello R, Bucolo C, Spedalieri G, Maltese A, Puglisi G (2002) Flurbiprofenloaded acrylate polymer nanosuspensions for ophthalmic application. Biomaterials 23: 3247-3255.

27. Stancampiano AHS, Acquaviva R, Campisi A, Vanella L, Ventura CA, et al (2006) Technological and biological characterization of idebenone-loaded solid lipid nanoparticles prepared by a modified solvent injection technique. $J$ Biomed Nanotechnol 2: 253-260.

28. Stancampiano AHS, Pignatello R, Puglisi G (2008) Effect of lipophilicity of dispersed drugs on the physicochemical and technological properties of solid lipid nanoparticles. Open Drug Deliv J 2: 26-32.

29. Leonardi A, Bucolo C, Drago F, Salomone S, Pignatello R (2014) Cationic solid lipid nanoparticles enhance ocular hypotensive effect of melatonin in rabbit. Int J Pharm 478: 180-186.

30. Leonardi A, Bucolo C, Romano GL, Platania CB, Drago F, et al. (2014) Influence of different surfactants on the technological properties and in vivo ocular tolerability of lipid nanoparticles. Int J Pharm 470: 133-140.

31. Cortesi R, Argnani R, Esposito E, Dalpiaz A, Scatturin A, et al. (2006) Cationic liposomes as potential carriers for ocular administration. Int J Pharm 317: $90-100$

32. del Pozo-Rodríguez A, Delgado D, Solinís MA, Gascón AR, Pedraz JL (2008) Solid lipid nanoparticles for retinal gene therapy: transfection and intracellula trafficking in RPE cells. Int J Pharm 360: 177-183.

33. BaAYaran E, Demirel M, SirmagÃ $1 / 4 \mid$ B, Yazan Y (2010) Cyclosporine-A incorporated cationic solid lipid nanoparticles for ocular delivery. J Microencapsul 27: 37-47

34. Kiernan JA (2001) Classification and naming of dyes, stains and fluorochromes. Biotech Histochem 76: 261-278. 